\title{
Immunohistochemical characterization of neoplastic cells of breast origin
}

\author{
Maria de las Mercedes Noriega', Fernando Paesani', Florencia Perazzo', Néstor Lago², Hugo Krupitzki, \\ Silvana Nieto ${ }^{1}$, Alejandro Garcia ${ }^{1}$, Alejandra Avagnina ${ }^{1}$, Boris Elsner ${ }^{1}$ and Valeria Cecilia Denninghoff ${ }^{1,3^{*}}$
}

\begin{abstract}
Background: After skin cancer, breast cancer is the most common malignancy in women. Tumors of unknown origin account for $5-15 \%$ of malignant neoplasms, with $1.5 \%$ being breast cancer. An immunohistochemical panel with conventional and newer markers, such as mammaglobin, was selected for the detection of neoplastic cells of breast origin. The specific objectives are: 1) to determine the sensitivity and specificity of the panel, with a special emphasis on the inclusion of the mammaglobin marker, and 2) to compare immunohistochemistry performed on whole tissue sections and on Tissue Micro-Array.
\end{abstract}

Methods: Twenty-nine metastatic breast tumors were included and assumed as tumors of unknown origin. Other 48 biopsies of diverse tissues were selected and assumed as negative controls. Tissue Micro-Array was performed. Immunohistochemistry for mammaglobin, gross cystic disease fluid protein-15, estrogen receptor, progesterone receptor and cytokeratin 7 was done.

Results: Mammaglobin positive staining was observed in 10/29 cases, in 13/29 cases for gross cystic disease fluid protein-15, in 20/29 cases for estrogen receptor, in 9/29 cases for progesterone receptor, and in 25/29 cases for cytokeratin 7. Among the negative controls, mammaglobin was positive in $2 / 48$, and gross cystic disease fluid protein-15 in 4/48.

Conclusions: The inclusion of MAG antibody in the immunohistochemical panel for the detection of tumors of unknown origin contributed to the detection of metastasis of breast cancer. The diagnostic strategy with the highest positive predictive value (88\%) included hormone receptors and mammaglobin in serial manner.

Virtual slides: The virtual slide(s) for this article can be found here: http://www.diagnosticpathology.diagnomx.eu/ vs/1366310812718988

Keywords: Tumors of unknown origin, Breast, Mammaglobin, Immunohistochemistry

\section{Background}

After skin cancer, breast cancer is the most common malignancy in women, accounting for $16 \%$ of all cancers in women [1]. Tumors of unknown origin represent a heterogeneous group of tumors that first manifest as metastasis in a patient with unknown history of disease, where the assessment fails to identify the primary tumor site at diagnosis. Tumors of unknown origin account

\footnotetext{
* Correspondence: vdenninghoff@cemic.edu.ar

'Centro de Educación Médica e Investigaciones Clínicas "Norberto Quirno" (CEMIC), Ciudad Autónoma de Buenos Aires, Argentina

${ }^{3}$ Miembro de la Carrera de Investigador del Consejo Nacional de Investigaciones Científicas y Técnicas (CONICET), Ciudad Autónoma de Buenos Aires, Argentina

Full list of author information is available at the end of the article
}

for 5 to $15 \%$ of all malignant neoplasms [2,3]. Breast cancer accounts for only $1.5 \%$ of tumors of unknown origin. Therefore, it is one of the first tumors to be ruled out in the presence of tumors of unknown origin in the female population. An adequate diagnosis has an impact on the treatment and prognosis of the disease [4]. Immunohistochemistry is a diagnostic tool for the classification of tumors of unknown origin, but few organspecific markers allow to accurately determine the origin of a metastasis, and the use of an immunohistochemical algorithm requires efficient and fast immunohistochemical testing [5]. To date, several breast markers have been postulated, such as beta-catenin, FAK, PIP, MUC1, PSE, e-cadherin, cytokeratin 7 (CK7), estrogen 
and progesterone receptors (ER and PR), gross cystic disease fluid protein-15 (GCDFP-15), mammaglobin (MAG)-A and MAG-B [6-9]. Fritzsche et al. showed $73.3 \%$ and $72.1 \%$ cytoplasmic positivity for GCDFP-15 and MAG, respectively, in invasive breast cancer (primary tumor) [10]. These findings significantly correlated with low tumor grade. Chia et al. demonstrated $47.8 \%$ and $11.3 \%$ positivity for MAG and GCDFP-15, respectively, in neoplastic cells of breast origin [11]. On the other hand, Takeda et al. found a sensitivity of $45 \%$ and $50 \%$ for GCDFP-15 and MAG, respectively, in pulmonary and pleural metastasis from breast cancer [12]. Moreover, Bhargava et al. showed positivity in $55.4 \%$ and $23.1 \%$ for MAG and GCDFP-15, respectively, in breast carcinomas as primary tumors [13]. None of them is specific for this type of neoplasm, and they all express uneven positivity in other malignancies. In addition, their sensitivity for breast cancer is variable, hence the need to use them as panels and correlate the results with the morphology of the tumor. Used alone, MAG-A could be the marker of choice to identify a tumor of breast origin [14]. According to these findings, this novel antibody may be included in an immunohistochemical panel. Antibodies used for the diagnosis of breast carcinomas were analyzed. To our knowledge, none of them is sensitive and specific enough to be used alone. Therefore, there is no Gold Standard available for breast carcinoma. The aim of this study was to determine the specificity and sensitivity of both the antibodies alone and the panel as a whole, using a panel of immunohistochemistry: CK7, hormone receptors (estrogen and progesterone), GCDFP-15 and MAG. We hypothesize that the inclusion of the MAG antibody to the immunohistochemical panel already routinely used would increase the positive predictive value in the detection of breast tumors of unknown origin.

\section{Methods}

The population consisted of 77 patients (29 cases and 48 negative controls). Twenty-nine cases were selected and followed at CEMIC Laboratory of Pathology. Samples were collected from both the primary breast tumor and its metastases at different anatomical sites. The 29 metastases were considered as tumors of unknown origin, despite the known origin of the breast tumor. Furthermore, another 48 biopsies were selected, including 42 different samples of primary or metastatic non-mammary tumors, and 6 non-neoplastic tissue biopsies. These samples were used as immunohistochemical negative controls, with all the possible sites of breast tumor metastasis included.

\section{Immunohistochemistry}

Four- to five-micron tissue sections were done and stained with hematoxylin-eosin, whereas 3-4- $\mu \mathrm{m}$ tissue sections (paraffin blocks and Tissue Micro-Array) were used for immunohistochemistry. The following monoclonal antibodies were used: MAG clone 304-1A5 (DAKO, Carpinteria, CA 93013, USA), CK7 clone OVTL 12/30 (Dako, Carpinteria, CA 93013, USA), ER clone 1D5 (DAKO, Carpinteria, CA 93013, USA), PR clone 16 (Novocastra Laboratories Ltd. Balliol Business Park West, Benton Lane, Newcastle Upon Tyne NE128EW United Kingdom), and GCDFP-15 clone 23 A 3 (DBS 1020 Serpentine Lane, FF114, Pleanton, CA 94566).

\section{Tissue micro-array}

A technique known as Tissue Micro-Array facilitates the simultaneous staining of many specimens on the same slide. It is the orderly distribution of hundreds of tissue samples in a tiny cylindrical paraffin block. Thus, since 1998, a large body of scientific evidence on Tissue Micro-Array has been reported, where this practical technique has been widely used. A blank paraffin-block was selected, which was punched at preset coordinates using Manual Tissue Arrayer I (Beecher Instruments), and $0.6 \mathrm{~mm}$ needles. At these sites, tumor samples drawn from the original blocks were inserted in turn. Three samples were punched from each tumor. Thus, the assembled block comprised a triplicate of each case.

\section{Statistical analysis}

Five different strategies were developed in order to define the diagnosis of metastatic breast cancer. For each strategy, sensitivity, specificity and positive predictive value were determined. The first two strategies were performed in parallel. The first one (strategy 1) considered as positive all those cases with hormone receptors (ER and PR), CK7 and GCDFP-15. The second one (strategy 2) included the same aforementioned panel, plus MAG. The remaining three (strategies 3,4 and 5) were considered in series, and they first analyzed hormone receptors (ER and PR). In those cases where hormone receptors were negative, either CK7 or MAG was added (strategies 3 and 4). In this sense, a strategy model was developed, basically considering ER and/or PR in the first place, followed by MAG and then CK7 (strategy 5).

\section{Table 1 Positive immunohistochemical results}

\begin{tabular}{lll}
\hline Marker & Cases $(\mathbf{n}=\mathbf{2 9})$ & $\begin{array}{l}\text { Negative } \\
\text { controls }(\mathbf{n}=\mathbf{4 8})\end{array}$ \\
\hline MAG & $10 / 29(34 \%)$ & $2 / 48(4 \%)$ \\
GCDFP-15 & $13 / 29(45 \%)$ & $4 / 48(8 \%)$ \\
ER & $20 / 29(69 \%)$ & $0 / 48(0 \%)$ \\
PR & $9 / 29(31 \%)$ & $0 / 48(0 \%)$ \\
CK7 & $25 / 29(86 \%)$ & $18 / 48(38 \%)$ \\
\hline
\end{tabular}

MAG: mammaglobin; GCDFP-15: gross cystic disease fluid protein; ER: estrogen receptors; PR: progesterone receptor; $C K \mathbf{K}$ : cytokeratin. 
Table 2 Statistical results for each marker

\begin{tabular}{llllllllll}
\hline Marker & TP & TN & FP & FN & $\begin{array}{l}\text { S } \\
\text { (\%) }\end{array}$ & $\begin{array}{l}\text { Sp } \\
\text { (\%) }\end{array}$ & $\begin{array}{l}\text { PPV } \\
\text { (\%) }\end{array}$ & +LR & -LR \\
\hline MAG & 10 & 40 & 2 & 19 & 34 & 95 & 83 & 7.24 & 0.69 \\
GCDFP-15 & 13 & 38 & 4 & 16 & 45 & 90 & 76 & 4.71 & 0.61 \\
HR & 20 & 41 & 1 & 9 & 69 & 98 & 95 & 29.0 & 0.32 \\
CK7 & 25 & 23 & 19 & 4 & 86 & 55 & 57 & 1.91 & 0.25
\end{tabular}

MAG: mammaglobin; GCDFP-15: gross cystic disease fluid protein; HR: estrogen and progesterone receptors; CK7: cytokeratin 7; TP: true positives; $\boldsymbol{T N}$ : true negatives; $\boldsymbol{F P}$ : false positive; $\boldsymbol{F N}$ : false negative; $\boldsymbol{S}$ : sensitivity; Sp: specificity; PPV: positive predictive value; + $\boldsymbol{L}$ : positive likelihood ratio; - LR: negative likelihood ratio.

\section{Results}

Positive staining is shown in Table 1 . Of $10 / 29$ positive metastatic breast carcinomas, 4 were invasive ductal carcinoma (IDC), 2 invasive lobular carcinoma, 3 were diagnosed as carcinomas of breast origin (not otherwise specified, NOS), and 1 was undifferentiated carcinoma. The sites of the metastases where MAG stained positively included brain, lymph node, pleura, ovary, bone and bone marrow. The immunoreactivity pattern ranged between focal and diffuse staining, with varying intensities.

On the other hand, the sites of the 13/29 metastases positive for GCDFP-15 were lymph node, brain, ovary, bone, bone marrow and pleura. The type of staining observed was similar to that of MAG.

In the cross analysis of antibodies, 8/29 cases were positive for both MAG and GCDFP-15. All cases positive for PR were also positive for ER. Statistics is shown in Tables 2 and 3.

Immunohistochemistry of tissue Micro-Array and complete sections of the tumor were compared, and no significant differences were observed, except for 2 cases of metastasis of breast origin. In one of them, staining with GCDFP-15 was not observed in the field punched for the Tissue Micro-Array. The same occurred with MAG antibody in the other case.

\section{Discussion}

For tumor diagnosis, primary location, morphology, histology and cytology, as well as clinical data, are crucial. According to the literature, the sensitivity and specificity of MAG and GCDFP-15 for the detection of breast cancer vary significantly, with MAG sensitivity being $80 \%$ to $48 \%$, and that of GCDFP-15 being $73 \%$ to $23 \%[9,13,15]$. In our study, MAG sensitivity was $34 \%$, and its specificity $83 \%$, while the sensitivity and specificity of GCDFP-15 were $44 \%$ and $79 \%$, respectively. While MAG sensitivity is lower than that of GCDFP-15, its positive predictive value is higher, being $83 \%$ for MAG and $76 \%$ for GCDFP- 15 . This shows that the inclusion of MAG antibody in the immunohistochemical panel would contribute to the detection of metastasis of breast cancer. According to the literature, CK7 antibody was positive in $25 / 29$ cases (86\%), which reveals an $83 \%$ positivity in breast cancer [16].

Immunomarkers in the negative control group revealed that: 1) MAG and GCDFP-15 were both positive in a case of pancreatic adenocarcinoma and another of cholangiocarcinoma. Review of the literature reports $10 \%$ of cholangiocarcinomas positive for MAG, while other source reveals MAG expression in intestinal tumors, mainly adenocarcinomas [17]; 2) GCDFP-15 showed positivity in a case of colorectal adenocarcinoma and another of large cell lung carcinoma. In these cases, the lack of MAG staining contributes to a higher positive predictive value, with more chances to detect metastasis of breast carcinoma. This shows that the inclusion of MAG in the immunohistochemical panel is highly convenient. 3) CK7 was positive in 20/48 of the negative controls included, which were mainly adenocarcinomas (12/48); 4) MAG is usually found in the female genital tract cells, and has been expressed in up to $77 \%$ of endometrial carcinomas (as primary tumor) $[18,19]$. However, in our study, female genital tract cells were not positive for this antibody.

As shown in Table 3, the addition of MAG to a basic immunohistochemical panel (ER. PR, CK7 and

Table 3 Immunohistochemical strategies, statistical results

\begin{tabular}{|c|c|c|c|c|c|c|c|c|c|c|}
\hline & Strategy & TP & $\mathrm{TN}$ & FP & FN & $\begin{array}{l}\text { S } \\
\text { (\%) }\end{array}$ & $\begin{array}{l}\text { Sp } \\
\text { (\%) }\end{array}$ & $\begin{array}{l}\text { PPV } \\
\text { (\%) }\end{array}$ & $+\mathrm{LR}$ & $-\mathrm{LR}$ \\
\hline & \multicolumn{10}{|c|}{ Markers considered in a parallel manner } \\
\hline 1 & $H R+C K 7+P-15$ & 10 & 42 & 0 & 19 & 35 & 100 & 100 & 999.999 & 0.66 \\
\hline \multirow[t]{2}{*}{2} & $\mathrm{HR}+\mathrm{CK} 7+\mathrm{P}-15+\mathrm{MAG}$ & 7 & 42 & 0 & 22 & 24 & 100 & 100 & 999.999 & 0.76 \\
\hline & \multicolumn{10}{|c|}{ Markers considered in a serial manner } \\
\hline 3 & $\mathrm{HR}-$ - CK7 & 28 & 20 & 22 & 1 & 97 & 48 & 56 & 1.84 & 0.07 \\
\hline 4 & HR-—MAG & 21 & 39 & 3 & 9 & 70 & 93 & 88 & 9.80 & 0.32 \\
\hline 5 & $\mathrm{HR}--\mathrm{MAG}-\mathrm{CK} 7$ & 28 & 22 & 20 & 1 & 97 & 52 & 58 & 2.03 & 0.07 \\
\hline
\end{tabular}

HR: estrogen and progesterone receptors; CK7: cytokeratin 7; P-15: gross cystic disease fluid protein (GCDFP-15); MAG: mammaglobin; TP: true positives; TN: true negatives; FP: false positive; FN: false negative; S: sensitivity; Sp: specificity; PPV: positive predictive value; + LR: positive likelihood ratio; - LR: negative likelihood ratio. 
GCDFP-15) is associated with lower sensitivity. The best immunohistochemical strategy seems to be number 4, which considers hormone receptors and the inclusion of MAG in a serial manner. Despite the low sensitivity of this diagnostic approach to metastatic carcinoma of breast origin, it offers high specificity (Table 3). As far as probability, the use of the immunohistochemical panel herein proposed proved categorical in only three cases, but allowed the exclusion of all the controls.

Jae-Ho et al. proposed the inclusion of MAG within the immunohistochemical panel for the detection of metastatic breast cancer [20]. Yang et al. concluded that MAG would be a good marker to be included in an immunohistochemical panel for differentiation between lung tumors and metastatic breast cancer in the lung [21]. MAG sensitivity was lower than that of GCDFP-15, but had a higher specificity. When combined, the whole sensitivity decreased, but an increase in specificity was observed, with no decrease in the positive predictive value. Overall, the use of the immunohistochemical panel contributes to the detection of metastasis of breast origin. Laurinavicius et al. showed the benefit of integrating digital image analysis into routine pathology, in order to determine breast ductal carcinoma immunohistochemical profiles by using multiple immunohistochemical biomarkers. Thus, the potential inclusion of MAG in these panels, as a tumors of unknown origin marker, would be promising for the diagnosis and treatment of these patients in the future $[22,23]$.

\section{Conclusions}

The inclusion of MAG antibody in the immunohistochemical panel for the detection of tumors of unknown origin contributed to the detection of metastasis of breast cancer. The diagnostic strategy with the highest positive predictive value ( $88 \%$ ) included hormone receptors and mammaglobin in serial manner.

\section{Abbreviations}

CK7: CytoKeratin 7; ER: Estrogen Receptor; FN: False Negative; FP: False Positive; MAG: Mammaglobin; GCDFP-15: Gross Cystic Disease Fluid Protein; PR: Progesterone Receptor; S: Sensitivity; Sp: Specificity.

\section{Competing interest}

All the authors declare that they have no competing interest in this protocol.

\section{Acknowledgments}

We thank Valeria Melia for her assistance in editing the English version of the manuscript, Myrthala Duguid at CEMIC University Institute library for her assistance in our literature review, and BANCO COMAFI for their financial support in running the immunohistochemical tests.

\section{Author details}

${ }^{1}$ Centro de Educación Médica e Investigaciones Clínicas "Norberto Quirno" (CEMIC), Ciudad Autónoma de Buenos Aires, Argentina. 'GEMATECH, Ciudad Autónoma de Buenos Aires, Argentina. ${ }^{3}$ Miembro de la Carrera de Investigador del Consejo Nacional de Investigaciones Científicas y Técnicas (CONICET), Ciudad Autónoma de Buenos Aires, Argentina.

\section{Authors' contributions}

All the authors of this protocol have made a substantial contribution to its conception and design, data collection, analysis and interpretation.

Received: 24 April 2012 Accepted: 22 June 2012

Published: 22 June 2012

\section{References}

1. Breast Cancer: Prevention and Control. World Health Organization. http://www.who.int/cancer/detection/breastcancer/en/index1.html.

2. Hainsworth JD, Greco FA: Management of patients with cancer of unknown primary site. Oncology 2000, 14:563-579.

3. Krementz ET, Cerise EJ, Foster DS, Morgan LR Jr: Metastases of undetermined source. Curr Probl Cancer 1979, 4:4-37.

4. Briasoulis E, Pavlidis N: Cancer of unknown Primary Origin. The Oncologist 1997, 2:142-152

5. ESMO Guidelines Task Force: ESMO Minimum Clinical Recommendations for diagnosis, adjuvant treatment and follow-up of cancers of unknown primary site. Ann Oncol 2001, 12:1057-1058.

6. Gillanders WE, Mikhitarian $K$, Hebert R, Mauldin PD, Palesch Y, Walters $C$, Urist MM, Mann GB, Doherty G, Herrmann VM, Hill AD, Eremin O, El-Sheemy M, Orr RK, Valle AA, Henderson MA, Dewitty RL, Sugg SL, Frykberg E, Yeh K, Bell RM, Metcalf JS, Elliott BM, Brothers T, Robison J, Mitas M, Cole DJ: Molecular detection of micrometastatic breast cancer in histopathologynegative axillary lymph nodes. Ann Surg 2004, 239:828-840.

7. Allende D, Denninghoff $V$, Avagnina A, Elsner B: Sentinel lymph nodes study: how to do it right? The Argentinean experience. Breast J 2008, 14:216-217.

8. Révillion F, Lhotellier V, Hornez L, Leroy A, Baranzelli MC, Giard S, Boneterre J, Pevrat JP: Real-time reverse-transcription PCR to quantify a panel of 19 genes in breast cancer: relationships with sentinel lymph node invasion. Int J Biol Markers 2008, 23:10-17.

9. Fleming TP, Watson MA: Mammaglobin, a breast-specific gene, and its utility as a marker for breast cancer. Ann N Y Acad Sci 2000, 923:78-89.

10. Fritzsche FR, Thomas A, Winzer KJ, Beyer B, Dankof A, Bellach J, Dahl E, Dietel M, Kristiansen G: Co-expression and prognostic value of gross cystic disease fluid protein 15 and mammaglobin in primary breast cancer. Histol Histopathol 2007, 22:1221-1230.

11. Chia SY, Thike AA, Cheok PY, Tan PH: Utility of mammaglobin and gross cystic disease fluid protein-15 (GCDFP-15) in confirming a breast origin for recurrent tumors. Breast 2010, 19:355-359.

12. Takeda Y, Tsuta K, Shibuki Y, Hoshino T, Tochigi N, Maeshima AM, Asamura $H$, Sasajima $Y$, Ito T, Matsuno $Y$ : Analysis of expression patterns of breast cancer-specific markers (mammaglobin and gross cystic disease fluid protein 15) in lung and pleural tumors. Arch Pathol Lab Med 2008, 132:239-243.

13. Bhargava R, Beriwal S, Dabbs DJ: Mammaglobin vs GCDFP-15: an immunohistologic validation survey for sensitivity and specificity. Am J Clin Pathol 2007, 127:103-113.

14. Liberman L: Pathologic analysis of sentinel lymph nodes in breast carcinoma. Cancer 2000, 88:971-977.

15. Sasaki E, Tsunoda N, Hatanaka Y, Mori N, Iwata H, Yatabe Y: Breast-specific expression of MGB1/mammaglobin: an examination of 480 tumors from various organs and clinicopathological analysis of MGB1-positive breast cancers. Mod Pathol 2007, 20:208-214.

16. Dennis JL, Hvidsten RT, Wit EC, Komorowski J, Bell AK, Downie I, Mooney J, Verbeke C, Bellamy C, Keith WN, Oien KA: Markers of Adenocarcinoma Characteristic of the Site of Origin: Development of a Diagnostic Algorithm. Clin Cancer Res 2005, 11:3766-3772.

17. Aihara T, Fujiwara Y, Miyake Y, Okami J, Okada Y, Iwao K, Sugita Y, Tomita N, Sakon M, Shiozaki H, Monden M: Mammaglobin B gene as a novel marker for lymph node micrometastasis in patients with abdominal cancers. Cancer Lett 2000, 150:79-84.

18. Watson MA, Darrow C, Zimonjic DB, Popescu NC, Fleming TP: Structure and Transcriptional regulation of the human mammaglobin gene, a breast cancer associated member of the uteroglobin gene family localized to Chromosome 11q13. Oncogene 1998, 16:817-824.

19. Kazuya O, Dabbs DJ, Bhargava R: Mammaglobin Expression in the female genital tract: Immunohistochemical Analysis in Benign and Neoplastic Endocervix and Endometrium. Inter J Gynecol Pathol 2008, 27:1418-1425. 
20. Han JH, Kang Y, Shin HC, Kim HS, Kang YM, Kim YB, Oh SY: Mammaglobin expression in lymph nodes is an important marker of metastatic breast carcinoma. Arch Pathol Lab Med 2003, 127:1330-1334.

21. Yang M, Nonaka D: A study of immunohistochemical differential expression in pulmonary and mammary carcinomas. Mod Pathol 2010, 23:654-661.

22. Laurinaviciene A, Dasevicius D, Ostapenko V, Jarmalaite S, Lazutka J, Laurinavicius A: Membrane connectivity estimated by digital image analysis of HER2 immunohistochemistry is concordant with visual scoring and fluorescence in situ hybridization results: algorithm evaluation on breast cancer tissue microarrays. Diagn Pathol 2011 6:87-96.

23. Laurinavicius A, Laurinaviciene A, Ostapenko V, Dasevicius D, Jarmalaite S, Lazutka J: Immunohistochemistry profiles of breast ductal carcinoma: factor analysis of digital image analysis data. Diagn Pathol 2012, 7:27-42.

doi:10.1186/1746-1596-7-73

Cite this article as: Noriega et al:: Immunohistochemical characterization of neoplastic cells of breast origin. Diagnostic Pathology 2012 7:73.

\section{Submit your next manuscript to BioMed Central and take full advantage of:}

- Convenient online submission

- Thorough peer review

- No space constraints or color figure charges

- Immediate publication on acceptance

- Inclusion in PubMed, CAS, Scopus and Google Scholar

- Research which is freely available for redistribution 